\title{
Tireoidite de Hashimoto e Doença Periodontal: Uma Revisão Narrativa
}

\author{
Hashimoto Thyroiditis and Periodontal Disease: A \\ Narrative Review
}

Ana MORAIS $\rrbracket^{1}$, Marta RESENDE ${ }^{2}$, José PEREIRA²

Acta Med Port 2016 Oct;29(10):651-657 - http://dx.doi.org/10.20344/amp.6704

RESUMO

Introdução: Atualmente há um crescente interesse no estudo das condições sistémicas com repercussões no periodonto. O objetivo deste artigo é determinar se existe uma relação entre a tireoidite de Hashimoto e a doença periodontal.

Material e Métodos: Fundamentada na periodontologia baseada na evidência e na combinação das expressões: 'Hashimoto disease'; 'Hypothyroidism'; 'Periodontal diseases'; 'Systemic diseases'; optou-se pela pesquisa e avaliação de artigos presentes nas bases de dados Medline, Scopus e Thomson Reuters, selecionando 30 para a análise na íntegra.

Resultados: Vários são os trabalhos desenvolvidos na procura de um melhor entendimento sobre a complexidade e patogénese das doenças periodontais, associando-as a múltiplas condições sistémicas. Atualmente a relação melhor descrita na literatura é a da artrite reumatoide; contudo, outras relações têm sido apontadas como é o caso da tireoidite de Hashimoto.

Discussão: A identificação de múltiplos mecanismos etiopatogénicos comuns à tireoidite de Hashimoto e à doença periodontal permite suspeitar de uma relação entre ambas. São exemplos a proliferação de linfócitos T helper 1 e 17 e suas repercussões periodontais, a disfunção do endotélio vascular da microcirculação gengival e a influência do hipotiroidismo sobre o metabolismo ósseo, nomeadamente ao nível do osso alveolar.

Conclusão: Existe plausibilidade biológica que suporta o estabelecimento de uma relação de associação entre a tireoidite de Hashimoto e a doença periodontal. Contudo, os estudos atuais não são suficientes para comprovarem um nexo causal entre estas duas patologias, devendo, os mesmos, ser elaborados num futuro próximo, de forma a melhor determinar a sua relação e interação.

Palavras-chave: Doenças de Hashimoto; Doença Periodontal; Revisão.

\section{ABSTRACT}

Introduction: Currently there is a growing interest in studying systemic conditions with impact on the periodontium. The aim of this article is to determinate if there is a relation between Hashimoto's thyroiditis and periodontal disease.

Material and Methods: Founded on periodontology based on evidence and in the combination of the keywords: 'Hashimoto disease'; 'Hypothyroidism'; 'Periodontal disease'; 'Systemic Diseases'; a search and evaluation of articles was conducted in Medline, Scopus and Thomson Reuters databases, selecting 30 articles for integral analysis.

Results: There have been developed several studies, searching for a better comprehension about the complexity and pathogenesis of periodontal diseases, associated them to multiple systemic conditions. Actually, the relationship that is best described in the literature is the one with rheumatoid arthritis; however, other relations have been pointed, such as Hashimoto's thyroiditis.

Discussion: The identification of multiple etiopathogenic mechanisms common to Hashimoto's thyroiditis and periodontal disease allow to suspect of a relation between them. Some of these mechanisms include the proliferation of lymphocytes T helper 1 and $T$ helper 17 and their impact on the periodontium, the dysfunction of vascular endothelium in gingival microcirculation and the influence of hypothyroidism on bone metabolism, namely on the alveolar bone.

Conclusion: There is biological plausibility to support the establishment of an association between Hashimoto's thyroiditis and periodontal disease. However, there are not enough studies to support the existence of a causal nexus between these two pathologies, so, in the future, more studies should be conducted to determinate there relation and interaction.

Keywords: Hashimoto Disease; Periodontal Diseases; Review.

\section{INTRODUÇÃO}

A doença periodontal é de etiologia multifatorial estando atualmente bem estabelecido o papel preponderante do biofilme dentário enquanto fator etiológico primário, não sendo, no entanto, apenas a presença dos agentes bacterianos patogénicos que determina a presença da doença. Existe uma resposta, por parte do hospedeiro, variável de indivíduo para indivíduo importante na determinação da gravidade da doença em indivíduos, bem como uma série de fatores endógenos e exógenos que modulam esta resposta, podendo predispor para a doença periodontal ou influenciar a sua taxa de progressão.
Alguns dos fatores de risco individuais para a doença periodontal são o género, a idade, o consumo de tabaco e álcool, a diabetes mellitus, a obesidade e a síndrome metabólica, a osteoporose, o défice de cálcio e vitamina $D$, o stress e fatores genéticos. ${ }^{1,2}$

Os mecanismos fisiopatológicos que ligam a doença periodontal com certas doenças autoimunes permanecem, ainda, não totalmente esclarecidos, mas acredita-se que existam elementos comuns a ambas. ${ }^{3}$ No que a estas diz respeito, atualmente, a relação melhor descrita na literatura é a da artrite reumatoide; contudo, outras relações têm sido

\footnotetext{
1. Faculdade de Medicina Dentária. Universidade do Porto. Porto. Portugal.

2. Departamento de Periodontologia. Faculdade de Medicina Dentária. Universidade do Porto. Porto. Portugal.

$\triangle$ Autor correspondente: Ana Morais. anajosefinamv@gmail.com
}

Recebido: 11 de junho de 2015 - Aceite: 02 de setembro de 2016 | Copyright @ Ordem dos Médicos 2016 
apontadas como é o caso da tireoidite de Hashimoto também designada de tireoidite linfocítica crónica. ${ }^{3,4}$

A tireoidite de Hashimoto é uma das tireoidites mais frequentes, sendo uma doença autoimune específica de órgão, classicamente caracterizada pela produção de anticorpos anti tireoideus que bloqueiam a síntese de hormonas tireoideas conduzindo ao hipotiroidismo. A sua incidência anual estimada é de 0,3 - 1,5 casos por cada 1000 pessoas ${ }^{7,8}$ e constitui a causa mais comum de bócio e hipotiroidismo em países em que a alimentação fornece um aporte de iodo suficiente..$^{5,6}$ Ocorre com prevalência superior no sexo feminino, com uma relação sexo feminino/ masculino na ordem dos 8 - 9:1. ${ }^{8}$ Algumas das suas principais manifestações clínicas são os sinais e sintomas de hipotiroidismo, bem como a presença de bócio tireoideu. ${ }^{5}$ Ao nível da cavidade oral esta poderá ainda manifestar-se por macroglossia, disgeusia, atrasos na erupção dentária, problemas periodontais e alterações na cicatrização dos tecidos. $^{9}$

A tireoidite de Hashimoto é, à semelhança da doença periodontal, uma doença multifatorial e complexa no que diz respeito à sua etiopatogenia, para a qual contribuem fatores genéticos, ambientais e endógenos que juntos levam à indução da autoimunidade, daí o interesse em estudar a relação entre estas duas patologias. . $^{5,10,11}$

São objetivos deste trabalho expor os conhecimentos atuais que ligam a tireoidite de Hashimoto com a doença periodontal, realizando uma revisão bibliográfica que permita perceber os mecanismos etiopatogénicos comuns às duas condições.

\section{MATERIAL E MÉTODOS}

Para a elaboração deste trabalho utilizou-se como instrumento de trabalho a periodontologia baseada na evidência. ${ }^{12}$ Utilizou-se o algoritmo analítico interventivo, representado esquematicamente na Fig. 1.

\section{RESULTADOS}

Vários trabalhos têm sido desenvolvidos na procura de um melhor entendimento sobre a complexidade e patogénese das doenças periodontais. Sabe-se hoje que várias condições sistémicas possuem uma associação com a doença peridontal. Para algumas delas, tais como a diabetes mellitus, ${ }^{1,5,6}$ as doenças coronárias, ${ }^{5}$ a ocorrência de acontecimentos adversos na gravidez, ${ }^{6}$ a osteoporose ${ }^{1}$ e a artrite reumatoide ${ }^{5}$ existe evidência científica comprovada que suporta a existência de uma relação de associação. No entanto, para outras condições como a obesidade, ${ }^{1,5}$ a síndrome metabólica, ${ }^{1,5}$ a doença pulmonar obstrutiva crónica, ${ }^{5}$ a pneumonia. ${ }^{5}$ a doença renal crónica ${ }^{5}$ e a síndrome de Sjogren ${ }^{6}$ existe apenas uma relação de plausibilidade biológica. Os mecanismos fisiopatológicos que ligam a doença periodontal com certas doenças autoimunes permanecem ainda não totalmente esclarecidos, mas acredita-se que existam mecanismos comuns a ambas. ${ }^{7}$ No que a estas diz respeito, atualmente a relação melhor descrita na literatura é a da artrite reumatoide; contudo, outras relações têm sido apontadas como é o caso da tireoidite de Hashimoto. ${ }^{7,8}$

\section{DISCUSSÃO}

Para a criação de um elo de ligação entre a tireoidite de Hashimoto e a doença periodontal torna-se necessário, em primeiro lugar, compreender e explorar cada um dos fatores etiológicos e mecanismos etiopatogénicos destas duas patologias.

Em seguida, expõem-se alguns dos mecanismos etiopatogénicos que ocorrem na tireoidite de Hashimoto e que simultaneamente se cruzam com aqueles que ocorrem na doença periodontal. Algumas das consequências clínicas, inerentes à tireoidite de Hashimoto podem também afetar a saúde do periodonto, pelo que esta perspetiva também foi explorada. Um resumo dos principais mecanismos abordados nesta revisão pode ser observado no esquema da Fig. 2.

\section{Fatores de suscetibilidade genética comuns à tireoidite de Hashimoto e à doença periodontal}

No caso da tireoidite de Hashimoto os fatores genéticos são preponderantes para a ocorrência da doença, sendo responsáveis por mais de $50 \%$ da suscetibilidade para a doença. ${ }^{5}$ Contudo, os mecanismos de suscetibilidade genética predisponentes para a doença são complexos e apenas algumas associações mostraram resultados consistentes.

Estudos genéticos apontam os genes imunomodeladores como principais responsáveis pela suscetibilidade genética para a tireoidite de Hashimoto. ${ }^{11}$ Os genes imunomodeladores identificados e confirmados são o gene Cytotoxic T lymphocyte-associated 4 (CTL-4) e o gene Protein tyrosine phosphatase, non-receptor type 22 (PTPN22). ${ }^{11}$

O gene CTLA-4 localizado no cromossoma 2 q33 é o principal gene envolvido na regulação negativa dos linfócitos T.5,11, Portanto, um polimorfismo neste gene resulta na ativação exagerada dos linfócitos $\mathrm{T}$ parecendo aumentar por si só o risco de desenvolver tireoidite de Hashimoto em 1,5 vezes. ${ }^{5,13}$

Atualmente ainda se desconhece qual a variante genética exata do CTL4 responsável pela autoimunidade e quais os mecanismos pelos quais ocorre essa autoimunidade. Contudo, três variantes genéticas principais têm sido estudadas, sendo uma delas o polimorfismo $A / G$ na posição 49 que resulta na substituição proteica do aminoácido alanina pelo aminoácido tirosina. ${ }^{14}$ Este mesmo polimorfismo tem também sido associado à suscetibilidade para a doença periodontal em alguns estudos recentes. ${ }^{15,16}$

No que diz respeito à suscetibilidade genética para a doença periodontal, ainda pouco se conhece. Os estudos genéticos até agora realizados são poucos e encontram-se ainda numa fase muito precoce. No entanto, algumas variações genéticas e polimorfismos têm sido apontados como estando associados a uma maior suscetibilidade para a doença periodontal e/ou para a sua maior ou menor gravidade. ${ }^{17}$ Constituem algumas destas variações genéticas e polimorfismos com variantes de risco genético para 
a doença periodontal que possuem uma forte evidência sugestiva de associação as seguintes: o gene glycosyltransferase 6 domain containing 1 (GLT6D1) alelo rs1537415, o gene CDKN2B antisense RNA 1 (ANRIL) alelos rs3217992 e rs1333048, o gene da cyclooxygenase 2 (COX2) alelos rs6681231, rs20417 e rs689466, o gene betadefensin 1
(DEFB1) alelo rs1047031 e o gene da Interleucina 10 (IL10) alelos rs61815643 e rs6667202. ${ }^{17}$

Uma grande variedade de doenças complexas, categoria em que se incluem a doença periodontal e outras doenças imunomediadas, como a tireoidite de Hashimoto, partilham muitas variantes genéticas de risco comuns,

\section{Formulou-se uma questão clínica}

Existe uma relação entre a tiroidite de Hashimoto e a doença periodontal?

(2) Procurou-se e selecionou-se a melhor evidencia cientifica disponivel

Fonte primária: Bases de dados eletrónicas PubMed, Scopus eThomson Reuters (ISI) consultadas entre os dias 18.12.2014 e 22.02.2015;

Combinação das palavras-chave: 'Hashimoto disease' OR 'Hypothyroidism' AND 'Periodontal diseases' AND 'Systemic diseases';

\section{Critérios de inclusão:}

- Artigos que relacionavam a tiroidite de Hashimoto ou o hipotiroidismo com a doença periodontal; e todos aqueles que abordavam a etiopatogenia da tiroide de Hashimoto e/ou doença periodontal.

- Artigos tipo Review, Systematic reviews, Clinical trials, Case report, Comparative study, Journal article e Meta-analysis.

- Artigos com texto integral disponível.

- Artigos escritos em português, espanhol ou inglês.

\section{Avaliou-se criticamente a evidência selecionada e refinou-se qualitativamente a seleção}

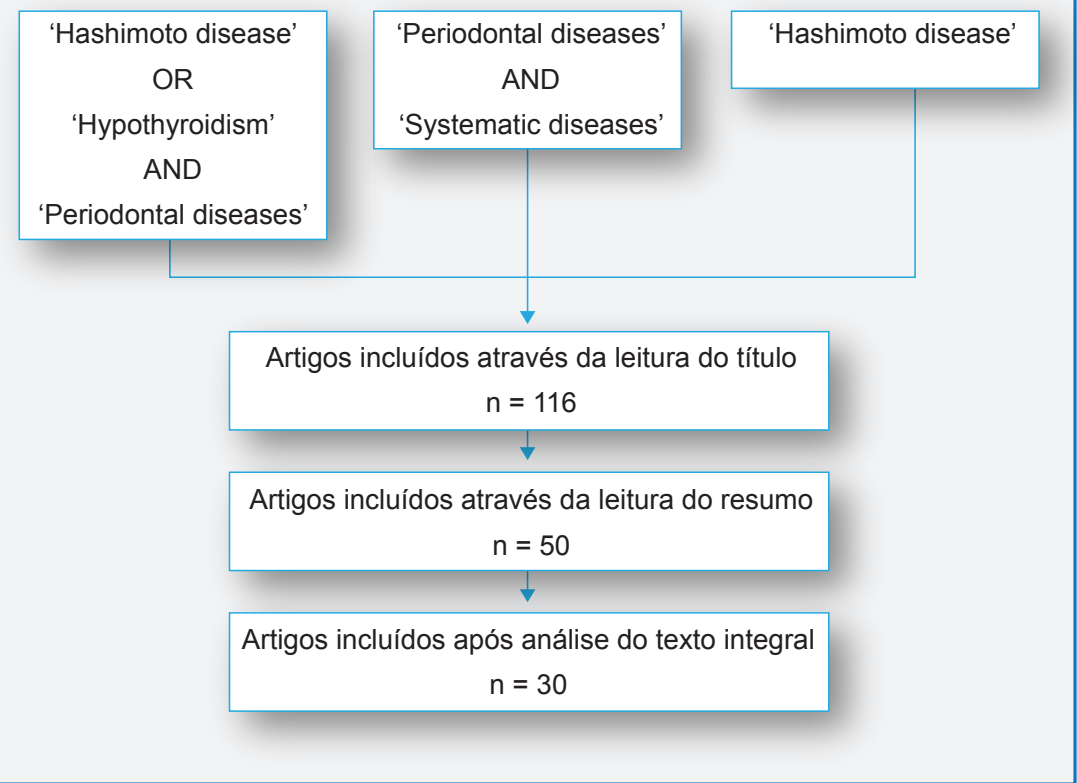

Figura 1 - Diagrama com o processo de seleção dos artigos 
fenómeno designado de pleiotropia. ${ }^{17}$ Este conceito de pleiotropia poderá no futuro ser aplicado em pesquisas que relacionem os genes de suscetibilidade para a doença periodontal com os de suscetibilidade para a tireoidite de Hashimoto, à semelhança do que já foi feito por exemplo para o gene ANRIL, que é um locus genético de grande suscetibilidade para a doença coronária e que está também associado com a doença periodontal. ${ }^{17}$ Desta forma, genes identificados com loci suscetíveis para a tireoidite de Hashimoto podem ser genes candidatos a serem estudados para uma associação com a doença periodontal, um desses potenciais genes é o CTL-4.

Houshmand et al (2012) encontraram uma correlação direta entre um polimorfismo no gene CTL-4 e a periodontite crónica em Iranianos. ${ }^{16}$ No entanto, um estudo semelhante realizados em indivíduos caucasianos provenientes da América do Norte revelou que não havia qualquer associação entre este polimorfismo e a periodontite crónica. ${ }^{18}$ Silva et al (2013) investigaram a associação entre o polimorfismo 49 A/G no gene $C T L-4$ e a periodontite agressiva em indivíduos brasileiros demonstrando que este polimorfismo pode conferir suscetibilidade para a periodontite agressiva com uma maior perda de aderência clínica. ${ }^{15}$ Uma interpretação plausível para explicar estes resultados discrepantes entre os diferentes estudos pode ser a heterogeneidade genética das populações, isto é a proveniência dos indivíduos estudados de diferentes etnias pode produzir mudanças na frequência dos alelos.

\section{O papel das células $\mathrm{T}$ helper 1 na tireoidite de Hashi- moto e na doença periodontal}

A autoimunidade na tireoide é induzida pelo aumento de células apresentadoras de antigénios (CAA) especializadas da tireoide ${ }^{19}$ desencadeado por sinais inflamatórios produzidos por dano ou necrose das células tireoideas. ${ }^{5}$ As CAA levam à ativação subsequente das células $T$ helper específicas para antigénios da tireoide, o que leva a uma alteração dos mecanismos de tolerância imunológica. ${ }^{5}$

Quando há um predomínio de células T helper 1 (Th1), produz-se um padrão de citocinas muito característico que conduz à destruição autoimune da tiróide, instalando-se a tireoidite de Hashimoto. ${ }^{5} \mathrm{O}$ interferão gama (IFN-ү), o fator de necrose tumoral alfa (TNF- $\alpha$ ) e a interleucina 2 (IL-2) constituem algumas destas citocinas. ${ }^{5} \mathrm{~A}$ libertação destas citocinas resulta na produção de um exuberante infiltrado linfocítico, na ativação do sistema complemento e citotoxicidade, favorecendo a imunidade celular e o desenvolvimento da apoptose celular. ${ }^{5}$

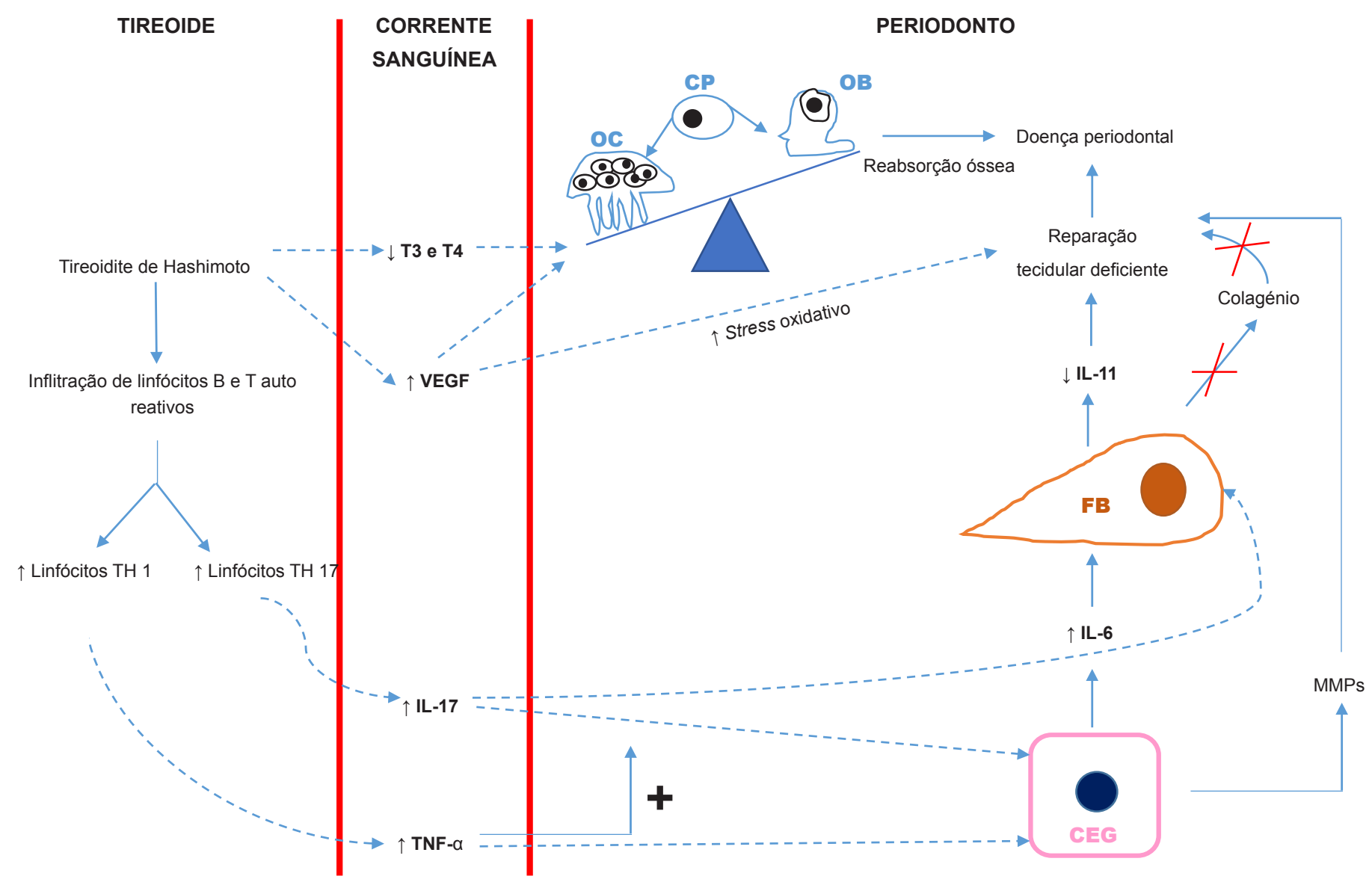

Figura 2 - Resumo dos mecanismos que podem relacionar a tireoidite de Hashimoto com a doença periodontal.

VEGF: Fator de crescimento endotelial vascular; T3: Tri-iodotironina; T4: Tiroxina; IL-17: Interleucina 17; TNF- $\alpha$ : Fator de necrose tumoral $\alpha$; CEG: Células do endotélio gengival; FB: Fibroblastos; CP: Célula percursora; OB: Osteoblastos; OC: Osteoclastos; +: Estimulação; $\uparrow$ : Aumento; $\downarrow$ : Diminuição; $><$ : Inibição; $\rightarrow$ : Eventos celulares; ;-) : Aferências humorais. 
A libertação persistente de mediadores inflamatórios, como acontece na tireoidite de Hashimoto pode levar à destruição dos tecidos periodontais. Mediadores inflamatórios como o TNF-a e a interleucina 1 beta (IL-1b) são responsáveis por iniciarem o processo de destruição dos tecidos periodontais através da geração de proteases, na sua maioria metaloproteinases (MMPs), que degradam a matriz extracelular; ativando os mecanismos de reabsorção óssea conduzidos pelo receptor acivator of $N F-K B$ ligand (RANKL), o que conduz à diferenciação e ativação dos osteoclastos por ligação com o receptor acivator of NF-KB $\left(\right.$ RANK). ${ }^{20}$

Recentemente, as células Th1 e T helper 17 (TH 17) têm também sido descritas como produtoras de citocinas potencialmente destrutivas, devido à sua capacidade para regularem positivamente outras citocinas pró-inflamatórias e a expressão do $R A N K L .{ }^{20}$

O balanço entre as respostas celular e humoral no hospedeiro é fortemente regulado pelo balanço de células Th1 e $T$ helper 2 (Th2), balanço este importante para a imunorregulação da doença periodontal. Tem sido sugerido que as células Th1 medeiam as lesões periodontais estáveis, enquanto as Th2 são responsáveis pela mediação da progressão das lesões periodontais. ${ }^{21}$

Desta forma, a proliferação de células Th1, evento obrigatório na patogénese da tireoidite de Hashimoto com a produção de um padrão de citocinas pró-inflamatórias a longo prazo pode favorecer a instalação e progressão da doença periodontal nestes doentes.

\section{A interleucina 17 como citocina pró-inflamatória co- mum na patogénese da tireoidite de Hashimoto e da doença periodontal}

A interleucina 17 (IL-17) produzida pelas células Th17 induz a secreção de múltiplas citocinas inflamatórias e a expressão de quimiocinas, envolvidas na resposta imune contra antigénios extracelulares e na indução de várias doenças autoimunes específicas de órgãos, tais como a artrite reumatoide, esclerose múltipla e psoríase.

Atualmente, as células Th17 e as suas citocinas inflamatórias secretadas têm vindo a ser reconhecidas como importantes mediadores em doenças autoimunes específicas de órgão, no entanto, o seu papel específico nas tireoidites, especialmente na tireoidite de Hashimoto permanece ainda relativamente desconhecido. ${ }^{22}$ Nicté et al sugeriram que existe um aumento da diferenciação dos linfócitos Th17 e uma síntese aumentada de citocinas Th17 na tireoidite de Hashimoto. ${ }^{22}$ Shi et al num estudo comparativo com pacientes com tireoidite de Hashimoto e indivíduos saudáveis, em que pretendiam clarificar o papel das células Th17 na patogénese da tireoidite de Hashimoto, encontraram concentrações plasmáticas de IL-17 mais elevadas no grupo de doentes com tireoidite de Hashimoto, comparativamente com o grupo de controlo, indicando que as células Th17 participam na patogénese da tireoidite de Hashimoto e que estas bem como os seus mediadores inflamatórios desempenham um papel importante nesta doença. ${ }^{22}$
O papel da IL-17 na patogénese da doença periodontal em humanos não é ainda bem conhecido. Contudo, estudos recentes demonstraram a presença desta interleucina em tecidos inflamados. ${ }^{21}$ Pensa-se que a IL-17 regule positivamente a expressão de interleucina 6 (IL-6), que por sua vez regula negativamente a expressão de interleucina 11 (IL-11) pelas células gengivais, o que sugere que a IL17 e a IL-11 desempenhem funções bastante diferentes na patogénese da doença periodontal. Estes estudos sugerem também que a IL-17 possui propriedades pró-inflamatórias, enquanto a IL-11 possui propriedades anti-inflamatórias. ${ }^{21}$ A IL-17 tem por isso, sido reportada como um regulador positivo para a síntese de citocinas pró-inflamatórias pelos macrófagos e possui sinergia com o TNF-a na síntese de IL-6 in vitro. ${ }^{21}$ Neste contexto, R.B. Johson et al propõem que a reparação tecidular deficiente dos tecidos periodontais poderá resultar da diminuição da IL-11 e aumento da concentração de IL-6 no endotélio gengival, regulada pela IL-17, conduzindo à instalação da doença periodontal. ${ }^{21} \mathrm{Em}$ adição, estes autores também referem que a produção de IL-17 pelas células T é o principal indutor da síntese de citocinas e inibidores da síntese de colagénio. ${ }^{21}$

Portanto, a IL-17 desempenha um importante papel como marcador inflamatório comum na tireoidite de Hashimoto e na doença periodontal.

\section{O modelo da disfunção endotelial}

Scardina e Messina propuseram a disfunção endotelial dos capilares sanguíneos da microcirculação gengival como fator de risco para a doença periodontal em doentes com tireoidite de Hashimoto. Estes autores verificaram que em pacientes com tireoidite de Hashimoto os capilares da microcirculação gengival provenientes da região interdentária apresentavam um diâmetro capilar diminuído, uma maior densidade capilar e uma maior tortuosidade na sua forma quando comparados com os capilares de indivíduos saudáveis. ${ }^{23}$

A maior densidade capilar nos capilares gengivais nos doentes com tireoidite de Hashimoto está correlacionada com a regulação positiva do fator de crescimento vascular endotelial (VEGF) presente em doentes com tireoidite de Hashimoto. ${ }^{23}$

O VEGF é uma glicoproteína produzida por muitas células, incluindo os monócitos/macrófagos, sendo induzido por fatores anti-inflamatórios como o fator de crescimento transformante beta (TGF- $\beta$ ). Este fator de crescimento induz a migração e proliferação das células do endotélio vascular, aumentando a permeabilidade vascular. O VEGF e o TGF- $\beta$ podem ser encontrados no epitélio tireoideu normal, na doença de Graves, na tireoidite de Hashimoto e em neoplasias da tireoide pelo que tem sido sugerido que estes sejam importantes para a função tireoidea e para o desenvolvimento de desordens da tireoide. Além disso, ambos os fatores exercem o seu efeito sobre a tireoide regulando a expressão de radicais livres de oxigénio como o óxido nítrico. O óxido nítrico possui várias funções, incluindo vasodilatação, neuro transmissão e regulação imune. ${ }^{24}$ 
Relativamente ao papel do VEGF na doença periodontal, estudos demonstraram que pacientes com periodontite possuíam níveis mais elevados de VEGF em locais de doença ativa do que em locais saudáveis. ${ }^{25}$ Para além do seu papel na regulação da angiogénese também se pensa que o VEGF desempenhe um papel importante na regulação da remodelação óssea, nomeadamente, na atração de células endoteliais e osteoclastos e estimulando a diferenciação dos osteoblastos. ${ }^{25} \mathrm{~A}$ sua possível contribuição para a progressão da doença periodontal foi suportada por um estudo que reporta a presença de concentrações mais elevadas de VEGF em gengivas inflamadas adjacentes a bolsas com profundidades de sondagem de 4 - $6 \mathrm{~mm} .{ }^{25}$ Neste sentido, especula-se que o VEGF possa ser um importante fator na progressão da gengivite para a periodontite. ${ }^{25}$

Em suma, o estado de inflamação crónica permanente que caracteriza a tireoidite de Hashimoto a longo prazo, bem como a regulação positiva do VEGF presente nestes doentes contribui para a disfunção endotelial dos capilares sanguíneos e aumento da quantidade de óxido nítrico existente nos capilares sanguíneos pela via dependente da ciclooxigenase 2 (COX-2) conduzindo ao aumento do stress oxidativo com aumento das prostaglandinas e das citocinas inflamatórias conduzindo a longo prazo à doença periodontal. ${ }^{3,24}$

Por outro lado, uma microcirculação gengival alterada compromete também a primeira linha de defesa periodontal. ${ }^{24}$ Para as células responsáveis pela primeira linha de defesa atuarem, alguns recetores celulares têm que ser expressos em concordância com a parede do endotélio vascular. ${ }^{24}$ Como o primeiro passo da defesa não específica do hospedeiro está comprometido, o indivíduo fica mais vulnerável à infeção por microrganismos periodontais patogénicos. Esta falha no sistema de defesa tem particular importância, ainda mais nos pacientes com tireoidite de Hashimoto, em que a resposta imune especifica já se encontra alterada per si.

Por tudo isto, se compreende que é passível que pacientes com tireoidite de Hashimoto estejam mais vulneráveis à infeção periodontal por microrganismos patogénicos e apresentem uma pior resposta ao tratamento periodontal propiciada por um processo de cicatrização dos tecidos de suporte que ocorre de forma mais lenta e deficiente.

\section{A influência do hipotiroidismo característico da tireoi- dite de Hashimoto na perda de osso alveolar}

A tireoidite de Hashimoto origina quase sempre um estado de hipotiroidismo, sendo que muito raramente pode verificar-se alternância de hiper e hipotiroidismo. ${ }^{5} \mathrm{O}$ hipotiroidismo caracteriza-se pela secreção de níveis reduzidos de hormonas tireoideias, tri-iodotironina (T3) e tiroxina (T4) para a corrente sanguínea. Este estado de hipotiroidismo que ocorre na tireoidite de Hashimoto resulta da atrofia da glândula tireoide pela ação dos auto-anticorpos anti-tireoideus que bloqueiam a síntese de hormonas tireoideias, T3 e T4.

As hormonas T3 e T4 são fundamentais para o proces- samento do normal turnover ósseo. Dados histomorfométricos indicam que uma deficiência marcada de hormona tireoideia prolonga acentuadamente o ciclo de remodelação óssea e reduz o turnover ósseo. ${ }^{26}$ Assim, no hipotiroidismo o turnover ósseo processa-se de forma lenta, verificando-se um crescimento e maturação óssea atrasados em crianças. ${ }^{27,28,29}$ Os adultos com hipotiroidismo tendem a exibir osteosclerose e um risco aumentado de fraturas ósseas. ${ }^{27,28,29}$ Embora não seja um achado universal, tem sido descrito que o hipotiroidismo pode levar à diminuição da densidade mineral óssea. ${ }^{27,31}$ Estudos populacionais com largo número de participantes demonstram que o hipotiroidismo está associado ao aumento do risco de fratura óssea, em duas a três vezes, mesmo 10 anos após o diagnóstico desta condição. ${ }^{26}$ A deficiência da enzima deiodinase tipo II (D2), que gera a forma ativa da hormona tireoideia T3 parece promover a formação de ossos frágeis e com dureza reduzida, aumentando assim a suscetibilidade à fratura, uma vez que esta enzima desempenha um papel essencial nos osteoblastos, otimizando a resistência óssea e mineralização. ${ }^{28}$

A presença de recetores da hormona tireoideia (TRs) em osteoblastos sugere que as hormonas tireoideas possuam um efeito direto sobre o metabolismo ósseo. ${ }^{27}$ Tem sido proposto que as hormonas tireoideias têm um importante papel no controlo da reabsorção óssea através da sua ação sobre a osteoprogeterina (OPG), sobre o RANKL, e em fatores reguladores do metabolismo ósseo tais como a IL-6 e interleucina 8 (IL-8). ${ }^{27}$

Uma vez que mudanças nos mecanismos do metabolismo ósseo são fatores contributivos para a doença periodontal, é legítimo pensar que alterações nos níveis de hormonas tireoideias, nomeadamente o hipotiroidismo característico da tireoidite de Hashimoto, possa constituir um fator modulador da doença periodontal.

Feitosa et al avaliaram a influência das hormonas tireoideias sobre a perda óssea resultante da indução experimental de periodontite em ratos e na qualidade do osso alveolar de suporte. Estes autores concluíram, no seu estudo, que um estado de hipotiroidismo pode potenciar a perda de osso alveolar resultante da doença periodontal induzida em ratos. Para além disso, os resultados deste estudo demonstraram um aumento do número de células positivas para o Tartrate-resistant acid phosphatase (TRAP), um marcador para a reabsorção óssea, no hipotiroidismo, o que sugere que para além da importância da deficiência de hormonas tireoideas no estado geral de saúde, o hipotiroidismo também pode condicionar o estado periodontal do indivíduo. ${ }^{27}$

As hormonas tireoideias regulam várias ações leucocitárias tais como a ativação e a proliferação de diferentes linhagens celulares, incluindo os linfócitos B e T. ${ }^{28}$ Além disso, estas também participam na libertação de citocinas, tais como o IFN g e a IL-6. ${ }^{29}$ Desta forma, a diminuição dos níveis destas hormonas pode promover uma resposta imunogénica menos competente à infeção induzida pela periodontite. Contudo, mais estudos devem ser realizados de forma a conhecer especificamente o efeito das 
mudanças das hormonas tireoideias no sistema imunitário local do microambiente do periodonto. Desequilíbrios na produção das hormonas tireoideias também dificultam o processo de cicatrização e reparação tecidular, tanto do tecido ósseo como dos tecidos moles. ${ }^{30}$

\section{CONCLUSÃO}

De fato, existe plausibilidade biológica para suportar a existência de uma relação de associação entre a tireoidite de Hashimoto e a doença periodontal. Contudo, não existem estudos suficientes que comprovem uma relação de causalidade entre estas duas doenças.

Além disso, sendo ambas as doenças de etiologia multifatorial, existem múltiplos fatores suscetíveis de confundir e dificultar a execução destes estudos e o estabelecimento de uma possível relação de causalidade.

\section{REFERÊNCIAS}

1. Genco RJ, Borgnakke WS. Risk factors for periodontal disease. Periodontology 2000. 2013;62:59-94.

2. Dentino A, Lee S, Mailhot J, Hefti AF. Principles of periodontology. Periodontology 2000. 2013;61:16-53.

3. Patil BS, Patil S, Gururaj TR. Probable autoimmune causal relationship between periodontitis and Hashimotos thyroidits: a systemic review. Nigerian journal of clinical practice. 2011;14:253-61.

4. Patil BS, Giri GR. A clinical case report of Hashimoto's thyroiditis and its impact on the treatment of chronic periodontitis. Nigerian journal of clinical practice. 2012;15:112-4.

5. Melo M. Tireoidites autoimunes. Acta Med Port. 2006;19:387-94.

6. Vieira A, Carrilho F, Carvalheiro M. Tireoidites auto-imunes: apresentação clínica e tratamento. Rev Port Endocrinol Diabet Metabol. 2008;2:45-56.

7. Hiromatsu $\mathrm{Y}$, Satoh H, Amino N. Hashimoto's thyroiditis: history and future outlook. Hormones. 2013;12:12-8.

8. Li Y, Nishihara E, Kakudo K. Hashimoto's thyroiditis: old concepts and new insights. Current opinion in rheumatology. 2011;23:102-7.

9. Pinto A, Glick M. Management of patients with thyroid disease: oral health considerations. J Am Dent Assoc. 2002;133:849-58.

10. Jabrocka-Hybel A, Skalniak A, Piatkowski J, Pach D, HubalewskaDydejczyk A. How far are we from understanding the genetic basis of Hashimoto's thyroiditis? Int Rev Immunol. 2013;32:337-54.

11. Sgarbi JA, Maciel RM. Patogênese das doenças tiroidianas autoimunes. Arq Bras Endocrinol Metab. 2009;53:5-14.

12. Mata AD, Marques D, Silveira J, Marques J. Medicina dentária baseada na evidência: novas opções para velhas práticas. Rev Port Estomatol Med Dentária e Cir Maxilofac. 2008;49:31.

13. Brand OJ, Gough SC. Genetics of thyroid autoimmunity and the role of the TSHR. Molecular and cellular endocrinology. 2010;322:135-43.

14. Tomer Y. Genetic susceptibility to autoimmune thyroid disease: past, present, and future. Thyroid. 2010;20:715-25.

15. Silva MR, Moreira PR, da Costa GC, Saraiva AM, de Souza PE, Amormino SA, et al. Association of CD28 and CTLA-4 gene polymorphisms with aggressive periodontitis in Brazilians. Oral diseases. 2013;19:568-76.

16. Houshmand B, Rafiei A, Hajilooi M. Influence of cytotoxic T lymphocyte antigen-4 (CTLA-4) gene polymorphisms in periodontitis. Arch Oral Biol. 2012;57:1218-24.

17. Vaithilingam RD, Safii SH, Baharuddin NA, Ng CC, Cheong SC, Bartold PM, et al. Moving into a new era of periodontal genetic studies: relevance of large case-control samples using severe phenotypes for genome-wide association studies. J Periodontal Res. 2014;49:683-95.
Neste sentido, é necessário efetuar mais trabalhos que permitam explorar a ligação, entre estas duas condições.

Face às evidências apresentadas, parece razoável recomendar que os clínicos que dediquem parte da sua prática a estas doenças estejam atentos à saúde periodontal dos doentes com tireoidite de Hashimoto e que percebam porque é que nestes doentes os tratamentos periodontais podem não apresentar os resultados esperados.

\section{CONFLITOS DE INTERESSE}

Os autores declaram não terem qualquer conflito de interesse relativamente ao presente artigo.

\section{FONTES DE FINANCIAMENTO}

Não houve qualquer subsídio(s) ou bolsa(s) que contribuíssem para a realização deste trabalho.

18. Wohlfahrt JC, Wu T, Hodges JS, Hinrichs JE, Michalowicz BS. No association between selected candidate gene polymorphisms and severe chronic periodontitis. J Periodontol. 2006;77:426-36.

19. Fountoulakis S, Tsatsoulis A. On the pathogenesis of autoimmune thyroid disease: a unifying hypothesis. Clin Endocrinol. 2004;60:397409.

20. Garlet GP, Cardoso CR, Mariano FS, Claudino M, de Assis GF, Campanelli AP, et al. Regulatory $T$ cells attenuate experimental periodontitis progression in mice. J Clin Periodontol. 2010;37:591-600.

21. Pradeep AR, Hadge P, Chowdhry S, Patel S, Happy D. Exploring the role of Th1 cytokines: interleukin-17 and interleukin-18 in periodontal health and disease. J Oral Sci. 2009;51:261-6.

22. Shi $Y$, Wang $H$, Su Z, Chen J, Xue Y, Wang S, et al. Differentiation imbalance of Th1/Th17 in peripheral blood mononuclear cells might contribute to pathogenesis of Hashimoto's thyroiditis. Scand J Immunol. 2010;72:250-5

23. Scardina GA, Messina P. Modifications of interdental papilla microcirculation: a possible cause of periodontal disease in Hashimoto's thyroiditis? Ann Anat. 2008;190:258-63.

24. Vural P, Degirmencioglu S, Erden S, Gelincik A. The relationship between transforming growth factor-beta1, vascular endothelial growth factor, nitric oxide and Hashimoto's thyroiditis. Int Immunopharmacol. 2009;9:212-5.

25. Giannobile WV, Al-Shammari KF, Sarment DP. Matrix molecules and growth factors as indicators of periodontal disease activity. Periodontology 2000. 2003;31:125-34.

26. Gogakos AI, Duncan Bassett JH, Williams GR. Thyroid and bone. Arch Biochem Biophys. 2010;503:129-36.

27. Feitosa DS, Marques MR, Casati MZ, Sallum EA, Nociti FH Jr., de Toledo S. The influence of thyroid hormones on periodontitis-related bone loss and tooth-supporting alveolar bone: a histological study in rats. J Periodontal Res. 2009;44:472-8.

28. Allain TJ, Thomas MR, McGregor M, Salisbury R. A histomorphometric study of bone changes in thyroid dysfunction in rats. Bone. 1995;16:5059.

29. Vestergaard P, Mosekilde L. Fractures in patients with hyperthyroidism and hypothyroidism: a nationwide follow-up study in 16,249 patients. Thyroid. 2002;12:411-9.

30. Paraguassú GM, Pimentel PA, Santos MS, Figueiredo LM, Ramalho LM, Sarmento VA. Alterações ósseas e do sistema estomatognático associadas a doenças endócrino metabólicas. Rev Cubana Estomatol. 2013;50:422-35. 